\title{
DENSITY AND WATER ABSORPTION PROPERTIES OF PMMA REINFORCED BY PEANUT AND WALNUT SHELLS POWDERS USED IN DENTAL APPLICATIONS
}

\author{
Zainab Moaead Abdul Monem ${ }^{1}$ \\ Qahtan Adnan Hamad² \\ Jawad Kadhim Oleiwi ${ }^{3}$ \\ zainabalneamey@gmail.com \\ qah84@yahoo.com \\ $130041 @$ uotechnology.edu.iq \\ University of Technology, Material Engineering Department, Baghdad, Iraq
}

\begin{abstract}
Poly Methyl Methacrylate resin distinguished by its low impact and fatigue strength, there are many researches that will deal with these situations. In the current study the matrix was heat cured material powder of PMMA was reinforced with peanut and walnut Shells to PMMA base material, which commonly utilize in the applications of denture. these natural powders were added in various weights fraction $(4 \%, 8 \%$, and $12 \%)$, and with similar average particle size $(53 \mu \mathrm{m})$ and studied Density and water absorption properties. In this study the method used to prepare the specimens is Hand Lay-Up method. The results showed that the values of density are increased when the weight fractions of both reinforcing natural particles increased and the maximum value was obtained with adding peanut shells powder at (12 wt.\%.) $\left(1.206 \mathrm{gm} / \mathrm{cm}^{3}\right)$ for the composite specimens, while the values of water absorption Tests was decreased by increasing the weight fractions of both reinforcing powders peanut and walnut Shells in PMMA resin and The lowest values was obtained by adding peanut shells powder at $(12 \mathrm{wt} . \% \mathrm{P})(0.003 \%)$.
\end{abstract}

Keywords: PMMA, Peanut Shells Powder, Walnut Shells powder, Density, water absorption, Bio composite.

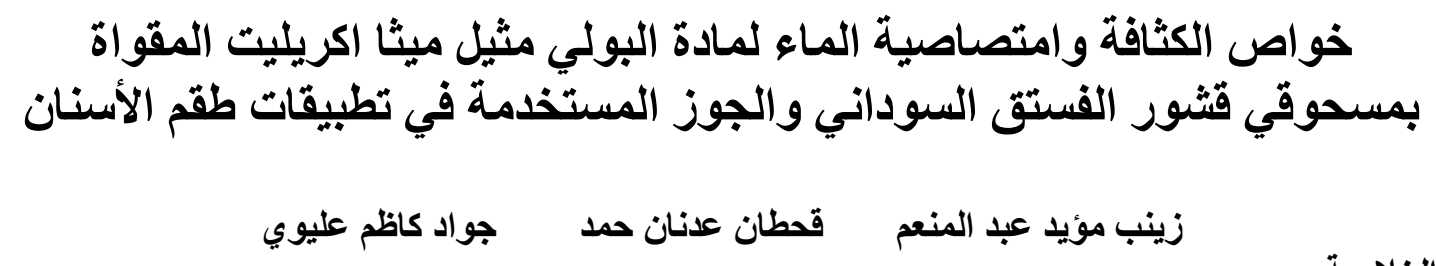

الخلاصة

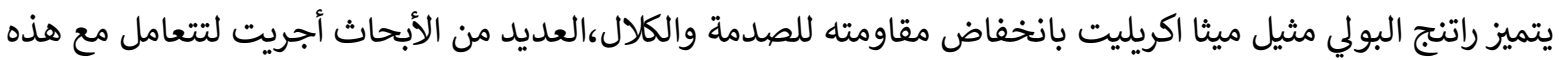

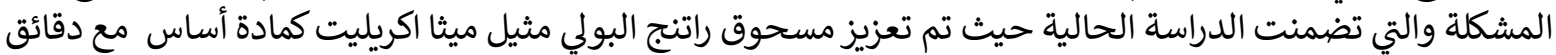

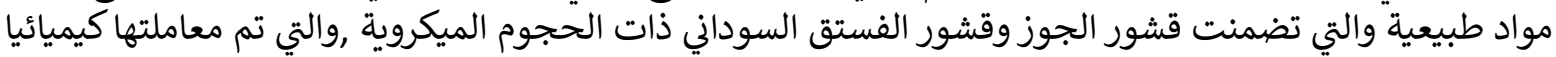

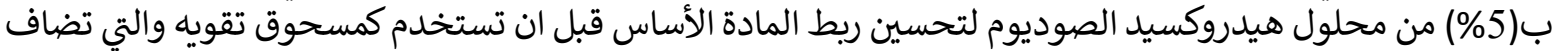

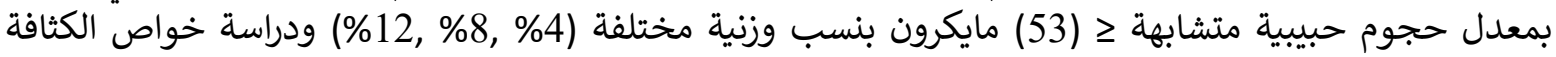

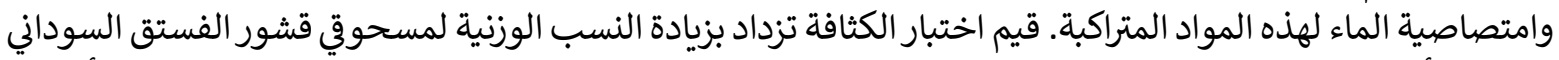

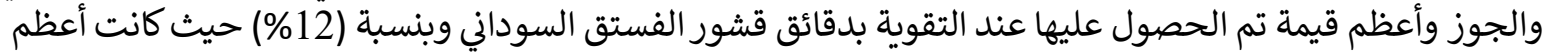

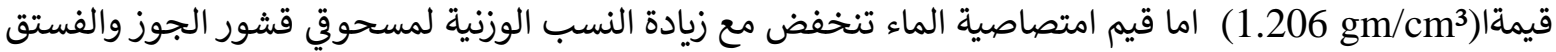

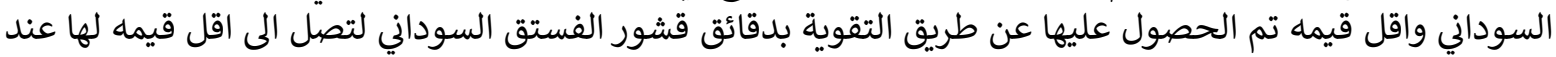

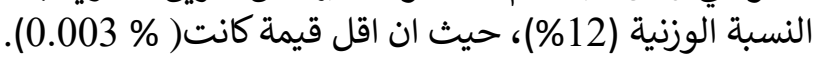

Received : 18-6-2020

Accepted : 15-7-2020 


\section{INTRODUCTION}

Poly (methyl methacrylate) (PMMA) has been excessively utilized as a major constitute of denture base polymer for many years, this material can be cracked or fractured when used in human body. One of the reasons of fracture is low impact resistance, fatigue or flexural. There are several influencing factors for denture fractures, these fractures are usually due to improper fitting of the dentures base. Poor closure defects in styling and production of the denture, in addition to innate stress in denture base that occurs with time Al Nakash, Suad (2013). scientists and Researchers worried about petroleum deterioration tried to push them to think about an renewable materials, so in recent years a proclivity forward the natural material such as (walnut shell, bamboo, coir, rise husk ,pistachio shell ... etc.) has increased over time K. Natarajan, and P.C. Balasubramanya(2013). Due to the high efficiency of nature materials over the synthetic one, that distinguished by their low cost, high density, renewability, biodegradability, and high degree of work flexibility making this material used as reinforcing material. In addition, the use of natural particles gives safe and healthy work conditions S.C. Venkateshappa et.al. (2010). Despite the advantages of natural materials, there have been a drawbacks, in which those they have poor mechanical properties compared to synthetic materials and high sensitivity to absorption of moisture due to hydrophilic nature which is unwanted for many other properties particularly stability of dimensions U.S. Bongarde and V.D. Shinde(2014), and this makes the chemical treatment essentially to enhance properties of the composite material by decreasing the hydrophilic of natural material which then effect on other properties like stability of dimensions and the matrix adhesion with reinforcing material.W. Abbas, A. A. Taqa, and N. A. Hatim.(2010), to study preferred properties (transverse strength, indentation hardness, color property, residual monomer, dimensional accuracy, porosity, infrared spectroscopy, and antimicrobial sensitivity) tests with different concentrations $(0.5 \%, 1 \%, 1.5 \%$, and $2 \%)$ of Nigella sativa and thyme as antibiotic materials. The results showed Additives from pure natural oil recommended by Nigella sativa and thyme at a concentration of $1.5 \%$ gives appropriate properties and antimicrobial after acrylic resin treatment of dental base, but thyme oil showed no effect on color after treatment in relation to the nigella. R., P. Sirisha, and M. R. Sankar (2014), a study was conducted to assess the hardness and tribological properties of PMMAbased poly (methyl methacrylate) for teeth by nanoscale. Bio-PMMA compounds containing $(2 \%, 4 \%, 6 \%, 8 \%, 12 \%, 16 \%$ and $20 \%)$ were prepared by weight from a nano full seashell and unfilled as a control sample. $2 \%$ of nan powder has been added to seashell. This addition had no significant on micro hardness. But it was found to increase the content of seashell nano powder, the value of micro hardness increased up to $12 \%$ and decreased significantly with $12 \%$ nan powder. The wear resistance property when adding a seashell nano powder with a compound reinforced the seashell beyond $12 \%$ showing less frictional force developed during the wear test. The $16 \%$ full compound and $20 \%$ frictional strength developed more than the developer in the $12 \%$ filled compound. It has been concluded that PMMA bio composite can be successfully strengthened by seashell nano powder with better properties at $12 \%$ of seashell nano powder content followed by composite filled with 8\%.A., Vipul, et al.(2015), to assess and compare (transverse strength, impact strength, surface hardness and water absorption properties) of $10 \%$ and $20 \%$ zirconia $\left(\mathrm{ZrO}_{2}\right)$ reinforced high-impact acrylic resins samples. The result was a marked increase in the transverse force in the reinforced samples when compared to the control group. Impact strength and surface hardness were found to have lower values compared to the control group. Water absorption has been found to increase with the addition of $10 \%$ and $20 \%$ zirconia $\left(\mathrm{ZrO}_{2}\right)$. H. A. Khalaf (2016), to evaluate the effect of adding a salinized mixture of siwak and polypropylene fibers on the base of PMMA teeth. Acrylic resin samples were prepared for each test (impact strength, transverse force, shear bonding strength, thermal conductivity, Shore D hardness, surface roughness and water 
absorption. (2\%) a silane mixture of siwak and polypropylene, statistical analysis showed that the flowery mixture of polypropylene and natural fibers (toothpicks) produced a significant increase of impact strength and highly significant increase of shear bond strength, the transverse strength, thermal conductivity, and hardness of D of heat-treated acrylic resin, while an insignificant increase were observed in surface properties and water absorption properties compared to non-fiber reinforced resin samples. Adding a salinized mixture of siwak and Polypropylene fibers in PMMA heat cured improved physical and mechanical testing properties. J.k.Oleiwi et.al.(2019), this research studying the influence of Pistachio Shell addition as a natural powder to PMMA matrix, that commonly used in denture applications. different weights fraction (3, 6, 9 and $12 \%$ wt.) of natural powder was added, and different average particle size $(53 \mu \mathrm{m}, 106 \mu \mathrm{m}, 150 \mu \mathrm{m}$, and $212 \mu \mathrm{m})$, to studying compression strength, hardness, and density properties. Statistically analyzed by SPSS (oneway ANOVA) evaluating the mean value and showed a large difference for each particle size. The maximum value of compression strength and surface hardness of PMMA composite specimens achieved at ( $9 \%$ wt.) of the filler particles. the results also showed that the values of density are increased with increasing the weight fraction of the filler particles for the composite specimens. S. E. Salih et.al. (2016), in the current research, efforts have been made to improve PMMA resin properties which is used for upper and lower prosthesis complete denture, four various types of nanoparticles was added, that are (fly ash, fly dust, zirconia and aluminum) added to poly (methyl methacrylate) (PMMA) with various volume fractions ratios $(1 \%, 2 \%$ and $3 \%)$, a matrix was cold cured resin (castavaria) is the new fluid resin (pour type). The reinforcing materials in this study involved (fly ash, fly dust and $\mathrm{ZrO}_{2}$ nanoparticles), and also water absorption effect. The results of the compression test concluded that the compressive strength values with and without water absorption effect increased with Nano powders adding (fly ash, fly dust, zirconia, and aluminum). the tests also showed that the highest compressive strength values for (PMMA: 2\% $\mathrm{nZrO}_{2}$ ) Nano composite. Whereas the highest compressive strength values for hybrid Nano composite for ((PMMA: 2\%fly ash) $\left.+\left(1 \% \mathrm{Al}+3 \% \mathrm{ZrO}_{2}\right)\right)$ hybrid Nano composite. furthermore, the results showed that the optimum compressive strength value under water absorption effect in the Nano composite material (PMMA+2\% fly dust), while the optimum compressive strength value under water absorption effect for hybrid Nano composite for ((PMMA: $2 \%$ fly dust $\left.)+\left(1 \% \mathrm{Al}+3 \% \mathrm{ZrO}_{2}\right)\right)$ hybrid Nano composite. J.K. Oleiwi et.al. (2018), this study discusses the influence of two natural fibers (siwak and bamboo) are used as reinforcing fibers for properties (water absorption and thermal conductivity) of PMMA. Three different lengths for two kinds of this fibers are used (2, 6 and 12mm) with three various concentrations (3, 6 and 9 wt. \%). The results indicate that the percent water absorption, thermal conductivity and thermal diffusivity increased with increase length of fiber and weight fraction. The highest water absorption values for bamboo and siwak specimens at (9wt.\%) and (12mm) fiber length. The maximum values of thermal conductivity and thermal diffusivity for bamboo specimens while for siwak specimens at optimum condition of (9wt. \%) and (12mm) fiber length. The aim of this study is to evaluate the density and water absorption of PMMA resin after reinforcing with Peanut and Walnut Shells powders with different weight fraction and similar particle size.

\section{MATERIALS AND METHODS}

\section{Peanut and Walnut Shells powder}

Figure (1, a and b) shows the peanut and walnut Shells while figure(2) shows the Walnut Shells Powders used as reinforcing material (powder) in three different weight fractions (4\%, $8 \%$, and $12 \%)$, and with similar average particle sizes of $(53 \mu \mathrm{m})$ in heat cure PMMA matrix material, to prepare bio composite specimens of prosthetic denture base. 


\begin{abstract}
Alkali treatment
The natural particles was immersed in alkali solution consisting of $5 \%(\mathrm{w} / \mathrm{v})$ of $(\mathrm{NaOH})$ in distilled water, at room temperature $\left(25 \mathrm{C}^{\circ}\right)(\mathrm{H}$. C. Obasi,et.al.2014 and Sihama I. Salih et.al,2017), 1:30 (w/v) representing the ratio of (powder /liquor), the treated powder washed by distilled water for several times to eliminate the residual $(\mathrm{NaOH})$ on its surface, until its reached neutral state $(\mathrm{pH}=7)$, after drying at room temperature for five days, and lastly placed in furnace at $\left(50-600^{\circ} \mathrm{C}\right)$ to ensure it was fully dried.
\end{abstract}

\title{
Preparation of bio composite specimens
}

A reinforcing material was weighting by using an electronic balance with precision of (0.0001) that used for the selected percentages of peanut and walnut shells powders. Peanut and walnut shells powders have been added to PMMA powder and mixed together until homogenous mixture is reached before adding to MMA liquid to start making bio composite specimens. The liquid monomer (MMA) and acrylic powder (PMMA) combined together according to standard ratio $(2.25: 1)$ as powder to liquid, 2.25 denotes to the PMMA powder weight ratio, and 1 denotes the liquid monomer weight ratio. Specimens have been shaped by pressing the proper amount of dough inside each cavity of the mould, then the mould covered by metallic plate fixed by 10 screws to achieve the pressure that is needed to form the specimens, which is 2.5 bar. Then the closed mould was put in path water where the temperature of water slowly rose to $100 \mathrm{C}^{\circ}$ about $2 \mathrm{hr}$, the aim of this behavior is to completion the composite specimens polymerization process, and to improve the physical properties that following these steps, the mould was still in the open air path water, to complete the polymerization process, and reach for the lowest level of the residual monomer the mould was cooled slowly. the specimens Then removed from the mould, with very smooth upper and low surfaces, and then finished to be ready to the subsequent testing (Jawad K. Oleiwi et.al.,2018).

\section{EXPEREMENTAL TEST}

In this test The density of the composite specimens was based on Archimedes method in accordance to (ASTM D 792), in which the specimens were weighted in the air, and then weighted at room temperature while submerged in distilled water, three digits balance (PS360/C/1) was used for weighting process (P. K. Mallick,2007).

\section{Water Absorption Test}

In this test The water absorption was accomplished according to (ASTM D1037-98), the samples were submerged in distilled water at room temperature for $(24 \mathrm{hr})$, then samples raised from the distilled water and the surface wiped away with the dry cloth and weighed by digital balance and the water abortion is obtained (Mohd, I. M. A. M.et.al.,2011).

\section{RESULTS AND DISSCUTION}

\section{Density Test}

Figure (3) illustrates the relationship between the weight fraction of (Peanut and Walnut Shells) of PMMA resin particles and the density of the specimens for the both types of these natural powders. It should be noted that the density values for both types of natural particles increased with the weight fraction increased. this is because the values of these particles are high in density as compared to the PMMA matrix. additionally, these particles are rendered to minimize or fill the voids and spaces within the PMMA matrix, that the SEM test showed. At last it can be resulted the reinforcing particles denser than the PMMA matrix with the same volume. It can also be noticed in this Figure that the additions of peanut shells particles have a significant effect on the density of composite specimens more than the particles of walnut shells. Thus, the calculated density values for composite specimens of the first group (peanut shells-PMMA) are higher than the density values of composite specimens for the second 
group (walnut shells -PMMA). This is due to the higher particle's density of peanut shells relative to the particles of walnut shells as shown. The density values for PMMA (as referenced) increased from $\left(1.195 \mathrm{gm} / \mathrm{cm}^{3}\right)$ to $\left(1.206 \mathrm{gm} / \mathrm{cm}^{3}\right)$ for (PMMA-12\% peanut shells) composite (ASTM Committee D-20 on Plastics, 2008 and Sihama I. Salih et.al.,2018).

\section{Water absorption Test}

Figure (4) Indicates the relationship between the weight fraction of particles in PMMA resin (peanut and walnut shells) and the water absorption percentage of the specimens for both groups. It can be noticed from this figure that the water absorption percentage values decreased as the weight fraction of particles increased for both Groups. This is because when the addition of fine particles such as (peanut or walnut shells) eliminates or fill all the spaces and porosities inside the PMMA matrix will be diminished or filled by these particles, Therefore, in the final result the amount of water absorption percentage of prepared composite specimens will be minimized(Polat, T. N., Karacaer et.al.,2003).It should also be observed in this Figure that the water absorption percentage values of for second group composite specimens (walnut shells-PMMA) are higher than the water absorption percentage values and value for first group composite specimens (peanut shells-PMMA),Thus, the water absorption value decreased from $(0.037 \%)$ composite for PMMA to $(0.003 \%)$ composite for (PMMA$12 \%$ peanut shells).

\section{CONCLOUTIONS}

The experimental studies for the composite materials which results in the preparation of this study leads to the following conclusions:

1. The Density of PMMA resin Reinforced with peanut and walnut shells particles, increased with increasing the weight fractions of both reinforcing particles and the maximum value was obtained with adding peanut shells powder, its maximum value at (12 wt.\%.) $\left(1.206 \mathrm{gm} / \mathrm{cm}^{3}\right)$. 2.water absorption Tests was decreased by increasing the weight fractions of both reinforcing powders peanut and walnut Shells in PMMA resin and the lowest values were obtained by adding peanut shells powder at (12 wt.\% P) The lowest values were $(0.003 \%)$.

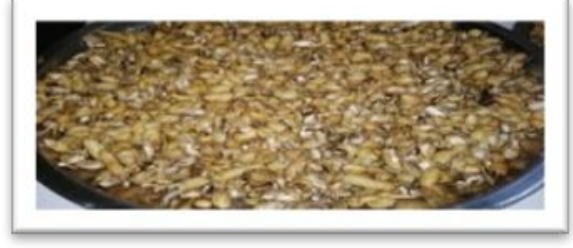

(a)

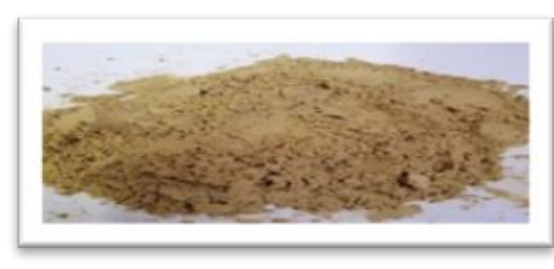

(b)

Fig. (1): Illustrate Peanut Shells Powders a-Before and b- After grinding process.

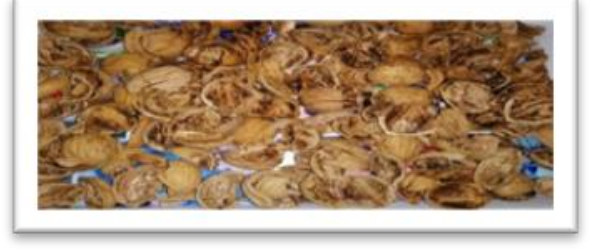

(a)

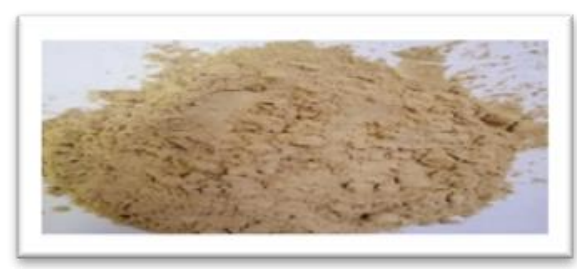

(b)

Fig. (2): Illustrate Walnut Shells Powders a-Before and b- After grinding process 


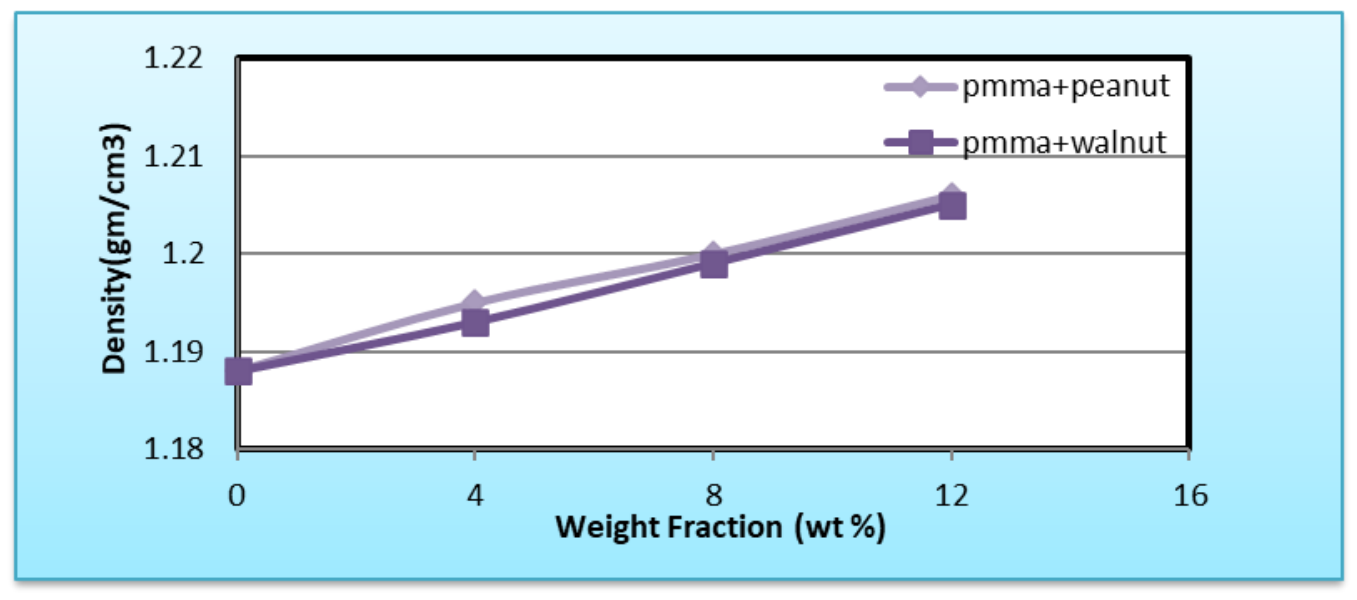

Fig. (3): The Relationship between Density and weight fraction of Peanut and Walnut Shells powders of PMMA Composite Materials at the same particle size.

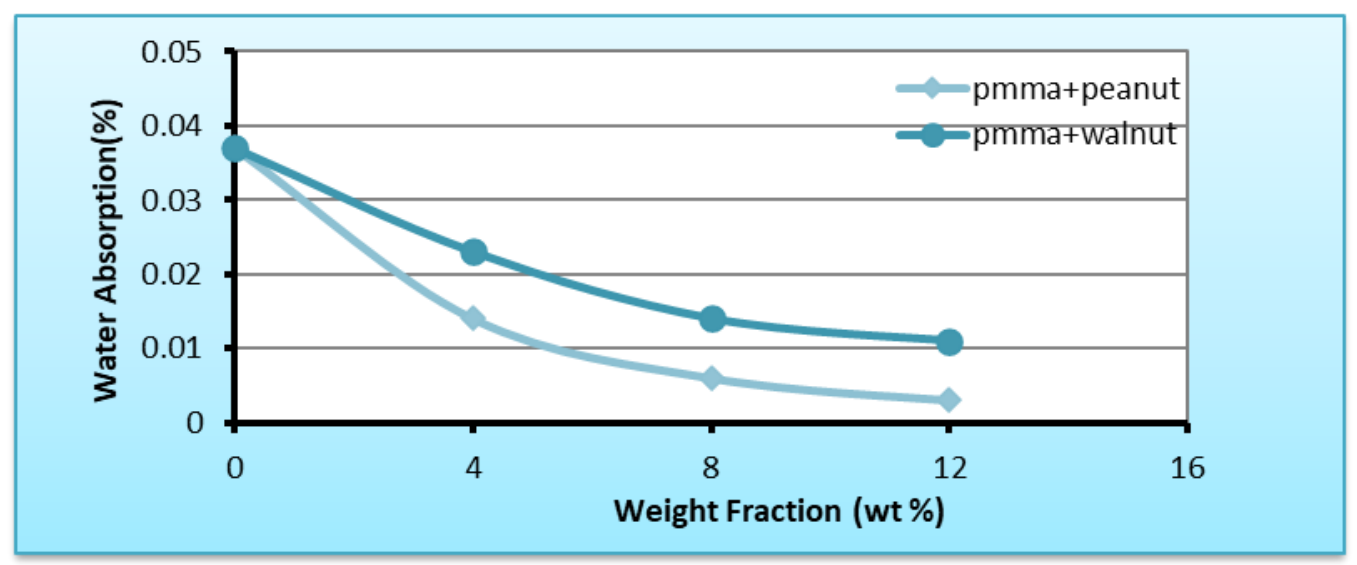

Fig. (4): The Relationship between water absorption and weight fraction of peanut and walnut shells powders of PMMA Composite Materials at the same particle size.

\section{REFERENCES}

Al Nakash, Suad., "The Influence of Different Chemical Surface Treatment on Transverse Strength of Repaired Heat Cure Acrylic Resins", Al-Rafidain University College for Sciences, Vol. 31, PP.93-115, (2013).

Abbas, W., Amer A. T., and Hatim N. A., "The Effect of Thyme and Nigella Oil on Some Properties of Acrylic Resin Denture Base", Al-Rafidain Dental Journal, Vol. 10, N.16, PP. 205-213, (2010).

Asopa, Vipul, et al., "A comparative evaluation of properties of zirconia reinforced high impact acrylic resin with that of high impact acrylic resin", The Saudi Journal for Dental Research, Vol.6, No.2, PP. 146-151, (2015).

ASTM Committee D-20 on Plastics," Standard Test Method for Density and Specific Gravity (Relative Density) of Plastics by Displacement D792-08", ASTM international, New York, (2008). 
H. C. Obasi, N.C Iheaturu, F. N. Onuoha, C. O. Chike-Onyegbula, M. N. Akanbi and V.O. Ezeh, "Influence of Alkali Treatment and Fiber Content on the Properties of Oil Palm Press Fiber Reinforced Epoxy Biocomposites", American Journal of Engineering Research, Vol.3, No.2, pp. 117-123,( 2014).

Jawad K. Oleiwi, Qahtan A. Hamad, Nada N. Kadhim," Study Compression, Hardness and Density properties of PMMA Reinforced by Natural Powder Used in Denture Base applications", Engineering and Technology Journal, Vol. 37, Part A, No. 12, (2019).

Jawad K. Oleiwi, Sihama I. Salih \& Hawazen S. Fadil," Water absorption and thermal properties of PMMA reinforced by natural fibers for denture applications", International Journal of Mechanical and Production Engineering Research and Development (IJMPERD), Vol. 8, Issue 3, pp. 1105-1116, Jun (2018).

Jawad K. Oleiwi, Qahtan A. Hamad, Hadil J. Abdul Rahman," Study thermal behavior of heat cure poly (methyle methacrylate) reinforced by bamboo and rice husk powders for denture applications", Al-Qadisiya journal for engineering sciences, Vol.11, No.4, (2018).

K. Natarajan, and P.C. Balasubramanya, "Mechanical and Morphological Study of Coir Fiber Reinforced Modified Epoxy Matrix Composites," International Journal of Emerging Technology and Advanced Engineering, Vol. 3, pp.583-587, (2013).

Mohd, I. M. A. M., Hamdan, S., Rahman, M. d. R. and Islam, M. D. S., " Liquefied Tropical Wood/Polypropylene Composites: Preparation and Physico-mechanical Properties", Materials Physics and Mechanics, Vol.11, No.2, PP. (126-136), (2011).

P. K. Mallick, "Fiber-Reinforced Composite: Materials, Manufacturing, and Design," International Standard Book, 3rd edition, (2007).

Polat, T. N., Karacaer, Ö., Tezvergil, A., Lassila, L. V., \& Vallittu, P. K., Water sorption, solubility and dimensional changes of denture base polymers reinforced with short glass fibers", Journal of biomaterials applications, 17(4), pp. 321-335, (2003).

S.C. Venkateshappa, B. Bennehalli, M.G.Kenchappa, and R. P. G. Ranganagowda, "Flexural Behaviour of Areca Fibers Composites," Bio Resources, Vol. 5, No. 3, pp. 1846-1858, (2010).

Sihama E. Salih, Jawad K. Oleiwi, Alaa Mohammed.T," Effect of Water Absorption on the Compressive Strength for PMMA Nano Composites and PMMA Hybrids Nano Composites Reinforced by Different Nanoparticles Used in Dental Applications", Eng. \&Tech.Journal, Vol.34, Part (A), No.14, (2016).

Sihama I. Salih, Jawad K. Oleiwi, Hwazen S. Fadhil," Preparation and Investigation of some Properties of Acrylic Resin Reinforced with Siwak Fiber Used for Denture Base Applications", Kurdistan Journal of Applied Research, Volume 2, Issue 3, August (2017). 
Sihama I. Salih, Jawad K. Oleiwi, Arkan S.Mohamed," Investigation of mechanical properties of pmma composite reinforced with different types of natural powder", ARPN Journal of Engineering and Applied Sciences, VOL. 13, NO. 22, NOVEMBER (2018).

U.S. Bongarde and V.D. Shinde, "Review on Natural Fiber Reinforcement Polymer Composites," International Journal of Engineering Science and Innovative Technology, Vol.3, No.2, (2014). 